\title{
Solar, Lunar and Venus Roles in Some Global Climatic Events
}

\author{
Malik Muhammad Nazeer \\ Islamabad, Pakistan \\ Email:Naz188nbsg@gmail.com
}

How to cite this paper: Nazeer, M.M. (2020) Solar, Lunar and Venus Roles in Some Global Climatic Events. Open Access Library Journal, 7: e6419.

https://doi.org/10.4236/oalib.1106419

Received: May 13, 2020

Accepted: September 4, 2020

Published: September 7, 2020

Copyright ( $) 2020$ by author(s) and Open Access Library Inc.

This work is licensed under the Creative Commons Attribution International License (CC BY 4.0).

http://creativecommons.org/licenses/by/4.0/

\section{(c) (i) Open Access}

\begin{abstract}
Any substantial and extraordinary role of a Solar, Lunar or Venus in the huge rise in present Global Heat Contents (GHC), Temperature, Hurricanes, storms, wildfires and resulting worldwide huge growth in calamities after 1965/70 was denied on the ground that no sizeable change in activities of these bodies matching in timings, stature and persistency with the Global Heat and Temperature (GHT), etc. was observed or reported. Yet their activities are contributing and these may be mishandled by any unscientific or illogical event or operation. Thus their roles have been reviewed in the light of some events and their possible correlation has been established for development planners and scientific community to revisit, review and revise the ongoing illogical and inappropriate activities for human welfare and safe existence of life on the earth Globe.
\end{abstract}

\section{Subject Areas}

Environmental Sciences, Geology

\section{Keywords}

Freon of Global Air Conditioner, 100 Years Frequency of North Atlantic Hurricanes, Indian Air Wheels and Monsoons, Solar, Lunar, and Venus Drag of Monsoons, Lunar Apsidal and Nodal Precessions Cycles Drive Floods in Pakistan, Venus Lapses Boosted Global Hazards

\section{Introduction}

From the mid of the last century, the Earth Global is passing through much alarming eras, extremely troublesome and disastrous for the mankind. The Global temperature, heat contents, storms, hurricanes, tsunamis, volcanic eruptions, wildfires, snowstorms, floods, earthquakes and epidemics, etc. has jolted the 
mankind again and again with extremely huge disasters and losses and thus $\mathrm{Na}-$ ture has forced it to critically review this situation to find out and rectify the causes and revisit its malfunctions and misdeeds fueling this train of disasters. In review of the literature about these on the Internet, it was frequently observed that rate of growth of these hazards has taken a very steep turn (Figure 1) by 1965-70 [1] [2]. The reports about Global heat contents (GHC) were extremely alarming [3] [4] [5] and generally leading to and driving most of these hazards. Any accelerating role of celestial bodies in this huge horrible turn was ruled out [6] [7] as there was no any persistent alarming change in their status matching it in timings, stature and persistency. However, their normal role in global climate drive may be made violent by any of the global flashers, detonator or catalyst as shown for Venus lapses and the Major North Atlantic Hurricanes, thus roles of these basic celestial initiators also need to be reviewed to know when, where and how much their activity can be boosted, so as to properly and amicably control

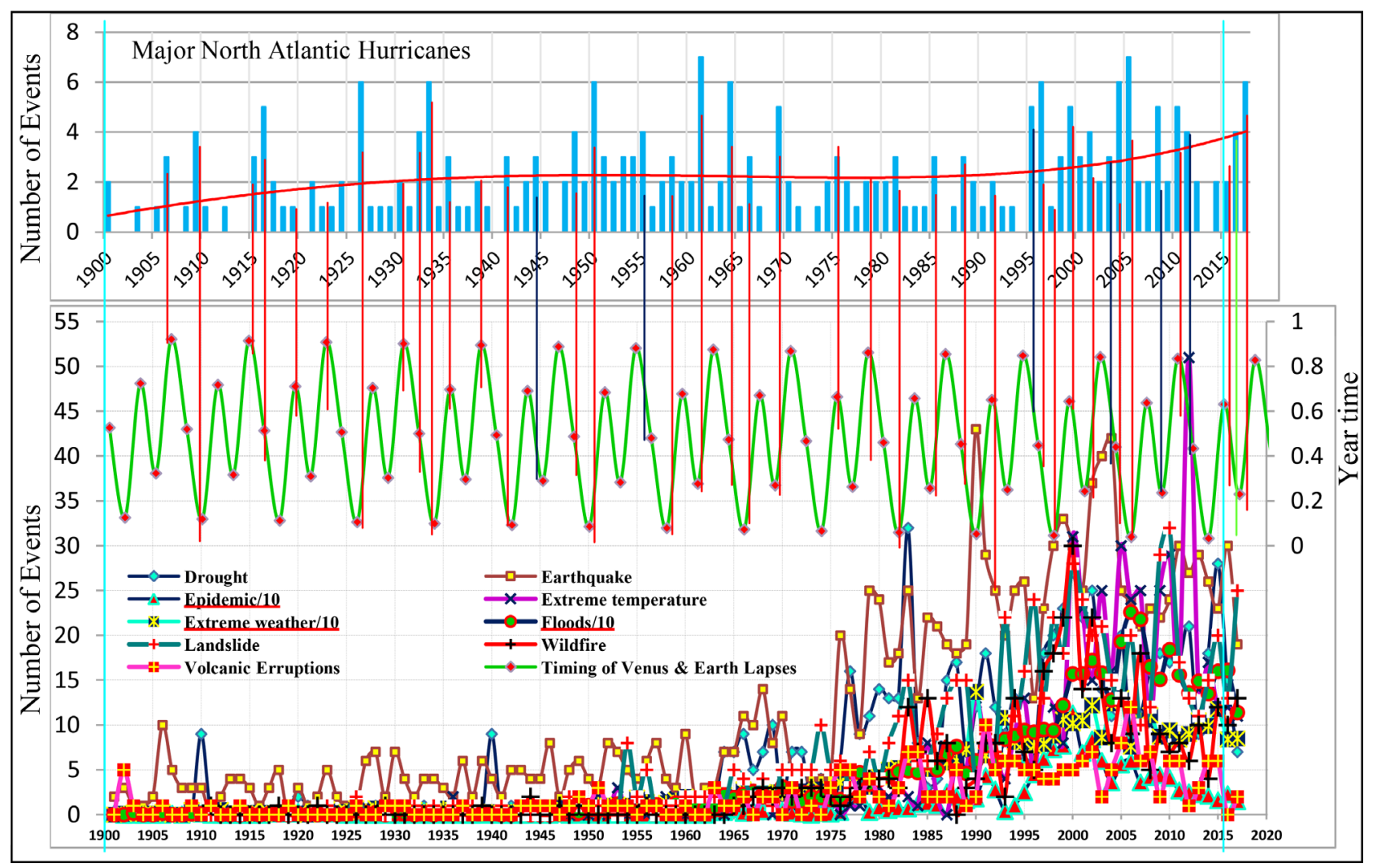

Figure 1. At the bottom in above figure are graphs of Global hazards growths [1] with time, showing their extraordinary growth after 1965. The three underlined with extraordinary values are reduced through dividing by 10. The Sun, Moon and Venus have systematic cyclic direct or indirect link with these hazards which can be seen by their mutual comparison. When compared individually, these hazards mostly show their matching occurrences with the Venus lapses plotted with its y-axis in a respective year domain versus 120 years time span. Although these Venus lapses have direct or indirect effects on these hazards, yet without any abrupt change in their activities, the said extraordinary growth of these hazards after 1965 cannot be linked to this and similarly to the others celestial bodies. At top is the sample of these hazards, the bar chart of Major North Atlantic Hurricanes over 1900-2017 years span [2] with its trend line (red) showing rise after 1975. Most of these show occurrence matching with Venus lapses evident from some main shown by red vertical lines links and a few blue lines where, either or both of the Venus lapses around it may have role in boosting their occurrence. 
any unwanted situation and as far as possible make it a contributor to the welfare of mankind. The fluctuations in graphs of Global Temperature [8] [9] [10] [11] when matched with the Global Major events, showed their mutual hand shaking with positive response and exchange protocol with quantity, quality and time bindings of most of these events [6]; may that be all USA Wildfire events; may those be World Wars No. 1 or 2, may those be Vietnam, Korea, Iraq and Afghanistan wars; may that be China and Indonesian huge wildfires; may that be nuclear bombing of Japan, etc.; all these have recorded their role on the Global temperature graphs [6], but none of these all individually nor all collectively can match with the role of Indus Basin Water Treaty of 1960 (IBWT) [12], neither in stature nor in persistency. Before the catch of IBWT, the GHC was observed to be continuously setting all bindings and barrier aside, while none alone, nor all together of its possible contributors could match it in quantity, quality and time, whereas unlimited persistency, consistency or continuity of GHC and GHT has expelled these contributors out of the catching net. A turning point came when [2] unearthed Oceanic heat contents estimates pointing out that 1) Atlantic Ocean, Southern Ocean, Indian Ocean and Pacific Ocean are in descending order of heat contents and 2) the Northern side of these Oceans dominates their Southern side. The Indian Ocean status in this list in spite of Northern dominancy and in spite of its $80 \%$ location on the Southern Hemisphere made the catch of this fish easy in a shallow water of a small pond. The Northern domination and Indian Ocean steered the search to India and Pakistan. The huge and persisting rise in Global heat, Temperature and other terrible events guided to the major persisting event initiated around 1960-70 within Indian Subcontinent. Thus the actual culprit was found to be the implementation of IBWT. It initiated water diversion of three Rivers (Ravi, Beas and Sutlej) in 1960 and completed their full diversion by 1970 and since then persistently continued their full flow diverted to India. But how was it contributing to this huge and terrible disaster of the Global ecosystems? From critical review of NASA video on recorded air movement throughout the year, particularly its Indian portion route [13] from June to November guided to the air wheel formation/generation at RCT, rolling westward following the tracks [14] (Figure 2) directed by earth rotation [15]. The earth energy budget [16] [17] pointed out the status of heat transport to the troposphere (condenser) by the water cycle and its matchless exploiting by RCT generated Indian Air wheel (IAW) with the help of water vapors (Freon) collected only from Southeastern Pakistan irrigated area by the said three rivers, collecting heat not only from Pakistan, but continuously from all its tracks (evaporator) over the earth globe (Figure 2) and continuously throwing it off to troposphere throughout its rolling of its all wheel. Thus the biggest culprit, IBWT, the drainer of Freon of GAC was caught red-handed with all proofs. Matching of North Atlantic Tropical Hurricanes timings with Indian coastal winds summer-autumn gap showed its footprints leading to the African western coast [6] [18], African west coastal wind pattern and timings, a huge South American 


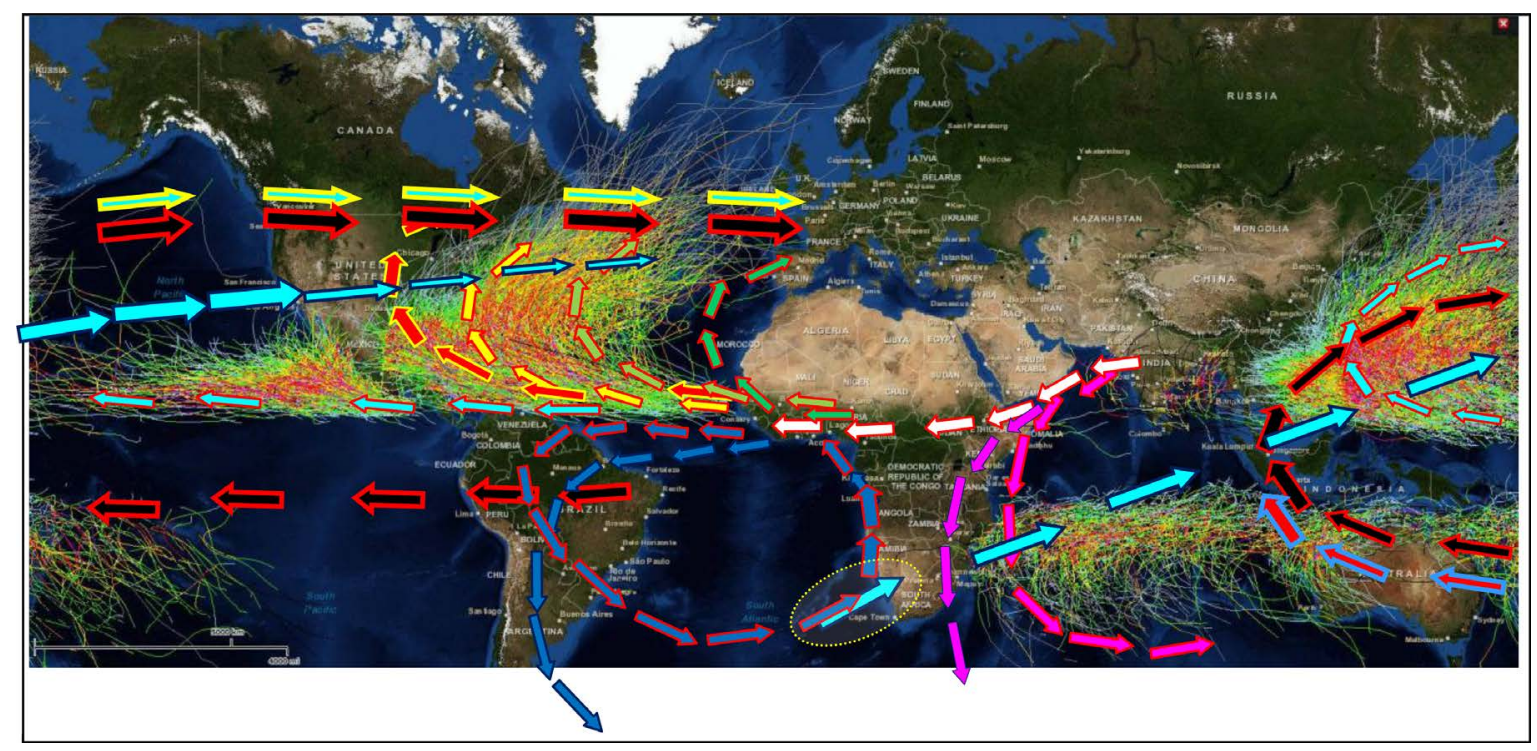

Figure 2. The tracks of various hurricanes groups, Atlantic, pacific and Indian Oceans are shown above. The North Atlantic group initiation is shown at India and Pakistan as westward rolling air wheels moving towards African western coast [20]. Red, Yellow and green arrows show their known various onward routes. The pink is the tracks of potion of Indian air wheels going to southern Ocean and Antarctica along the eastern coast of Africa. The Indus Basin Water Treaty of 1960 has role not only in boasting of Global Heat Contents, Global Temperature and all the North Atlantic Hurricanes (NAH) family, but it also has transcontinental role in cross over to Pacific and North Western Pacific hurricanes tribes as their continuation is shown above (red boundaries cyan arrows, transformation encircled) and boasting the USA bound/attacking pineapple express/atmospheric river (dark blue boundaries cyan arrows)and Europe bound wind and snow storms both from Africa (green arrows) and Canada (yellow boundary cyan arrows). The yellow track of NAH may shift to the tracks shown red, hitting central and northern states of USA as a result of Indian Monsoons [19] boasted by extreme Global heating and temperature and directed by African western coastal winds (blue arrows), all fueled by Indus Basin Water treaty (IBWT) of 1960.

mountain channelizing and reverting a potion of easterlies and IAW [7], their push and redirection by the Sothern westerly, a part directed to western coast of Africa and a part hitting Antarctica completed the cycle of NAH within the era of IBWT tragedy. The part of IAW crossing over to the Pacific Ocean and the part reverted by South American continent completed its GAC contributing components. Thus the Nature guided to the:

1) Logical sequential order to chain these information to recognize the Divinely mechanized Global air Conditioner (GAC);

2) Pattern of Global air movement system;

3) Role of Indian IAW in this scenario;

4) Role of IBWT implementation;

5) Logic behind the variation of heat contents of different Oceans;

6) Initiation of NAH in RCT deserts;

7) Global heat transportability by IAW with and without IBWT implementation.

During this, a few very important roles of celestial bodies were encountered which need detailed reviewing, setting the IBWT role and its aftermaths aside for the time beings. All the IAW trains formation, their propagation and toppling into NAH, crossover of these still vertical IAW to Pacific Ocean, operation 
of Natural Global Air Conditioner (GAC), NAH association with Indian Monsoons [19], 2017/18 Californian, USA [20], 2019's Brazilian and 2019/2020 Australian wildfire [21] with their transcontinental disaster and multiple strokes of further wildfires, heat waves, heavy wind and snow storms, heavy rains and huge floods all over the earth glob, USA bound Pineapple Express/Atmospheric River and Europe bound wind and snow storms both from Africa and Canada, most have roles of these Celestial bodies. Some of these roles in a few events or observations are discussed here below.

\section{Solar, Lunar and Venus Roles}

These three celestial bodies have very prominent, direct, short and long cyclic persistent roles on Monsoons, Oceanic tides, Easterlies, Westerly, GAC, IAW formation and propagation, GHT, NAH, Earthquakes, wide spread wildfire, Glaciers and movement of Avalanches, volcanic eruption on the Earth Globe. The common and most important thing in all these is the gravitational pull on the earth and its individual items, particularly loosely tied up with the main earth body like air/atmosphere, water in oceans and ponds, ice glaciers, molten lava, tectonic plates, rocks, mountains ridges, portions of earth plates loosened by earthquakes and volcanic eruptions depending upon their grip of the earth. The activity of this gravity varies much quickly on daily bases with earth rotation about its axes and annually with its rotation around the sun and positional cluster of all these celestial bodies with respect to the earth. The rotation of earth brings its said components/items on its surface in front of these celestial bodies at the rise of these bodies above the horizon (C-rise) and at the end at their setting down (C-setting) removes it from the view of that celestial body. The gravitational pull on these earthen items has three components (Figure 3 ). The component vertical to the earth surface (red) and the one horizontal, but perpendicular to earth surface moving direction (cyan) are both half sine wave with peak at (celestial body noon with respect to the body of earthen item) C-Noon, while the component along the direction of earth motion (blue) is half sine wave up to C-Noon in the direction of earth motion i.e. eastward, while after C-Noon it is again half sine wave, but in opposite direction, i.e. westward. The $2^{\text {nd }}$ one (cyan) is not much affective in most of the cases except where earthen body situation favors it much.

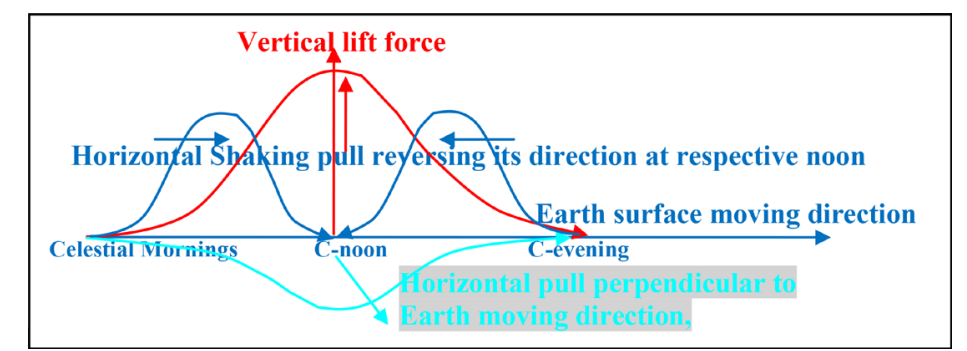

Figure 3. Direction and stature variations of three Components of pull of celestial body on earthen items are shown with respect to the movement of earth. 
The first one, however, is affective and has upward pull, while $3^{\text {rd }}$ one has daily cyclic shaking or jolting affect as long as the earthen item is in view of that celestial body. A critical point in this is that before C-Noon the pull is in the direction of earth eastward movement, all in phase, but after the C-Noon there is contention in between the earth grip on the item and the pull of celestial body and this situation disturbs the statuesque of that item.

\subsection{Sun Cyclic Role}

The Sun has various affects and activities, a few individually and some collectively with other celestial bodies. The sun heat and light are its individual affects on earth which vary with the earth's both movements; rotation about its polar axis and rotation about the sun along its elliptic orbit, both going at a time. The change of seasons, movements of air, growth and development of plants and vegetation, clouds formation and movement and rains are a few of its affects contributed by its heat, light and gravity variations with the earth's both motions.

\subsection{Venus Cycles}

The Venus has smaller orbit around the sun than earth and has 224.701 days cycle, while earth has 365.256 days cycle around the sun [22] [23] [24]. It catches the earth (laps or inferior conjunction) from back in its journey around sun in regular intervals of 583.9236 days (one year, 7 months, 6 days and 0.95 hours) as estimated below and it takes 5 lapses in nearly 8 (less 2.43 days/2 days 10 hours and 19 minutes) years to complete its cycle to be again at the position closest to the earth in about the same solar dates or season. If " $\mathrm{X}$ " is the time between two lapses, then at the next laps, the earth and Venus will have equal angles about the sun given by

$$
\begin{aligned}
& 360 \times X / 224.701-360=360 \times X / 365.256 \\
& \text { Or } X \times(1 / 224.701-1 / 365.256)=1 \\
& \text { Or } X=224.701 \times 365.256 /(365.256-224.701) \\
& \text { Or } X=224.701 \times 365.256 / 140.555 \\
& \text { Or } X=583.92365 \text { Days } \\
& \text { Or } X=1.5986695632652167247081499003439 \text { years }
\end{aligned}
$$

Or $\mathrm{X}=$ one year and 218.6676 Days Or $\mathrm{X}=$ one year, 7 months and 6 days and 57 minutes. Various Lapses are given in Table 1.

Table 1. Lapses numbers within venus cycle of 8 years.

\begin{tabular}{ccc}
\hline Lapses & No. of years & Rounded years \\
\hline 1 & 1.6 & 2 \\
2 & 3.2 & 3 \\
3 & 4.8 & 5 \\
4 & 6.4 & 6 \\
5 & 7.99335 & 8 \\
\hline
\end{tabular}


A laps, in which Sun is also approximately in line with Earth and Venus, is called Transit. The two last transits occurred on $9^{\text {th }}$ June, 2004 and 5 - 6 June, 2012 and the next one won't be until December 2117 after 105.5 years [22] [23] [24]. Transits of Venus also follow a peculiar pattern, two transits 8 years apart, then 105.5 years with no transits, then two transits 8 years apart, then 121.5 years with no transits, for a total cycle of 243 years-and thereby repeats the cycle [22] [23] [24]. The transits are more critical in their activities on the Earth than lapses due to maximum combined gravitational pull and drag by the Sun and Venus and the lapses also differ in some of their activities as per their orientations and timings.

\subsection{Moon or Lunar Cycles}

Moon is closest to the earth and has most effective and prominent roles through its number of cycles [25] [26]. The following are cyclic characteristics of the moon with respect to Sun and earth and these may have role in climate, monsoons, GHT, NAH and Global hazards etc.

i) Moon cycles on its elliptical path around earth in 27.3 days revolving about its own axis too in 24 hours [25].

ii) Moon average phase cycle (new moon to new moon) is of 29.5 days [25].

iii) New moon initiation is almost locked with the earth at about $40^{\circ}$ easts Longitude.

iv) Lunar 12 month year is of 354.5 days, whereas Solar year is of 365.256 days. Thus it has 10.75 days yearly lead with respect to sun. Thus, it requires cycle of 34 years for matching with solar season again.

v) It has critical four positions of its perigee shown at (a), (b), (c) and (d) in Figure 4(A) with respect to line of sun to earth (AESL) [25].

vi) $1-7,8-14,15-21 \& 22-28$ days monthly are 4 quarters per its monthly rotations around earth depending on its locations with respect to the sun.

vii) Apsidal precession or precession of the Moon's orbit is the rotation of major axis of the Moon's elliptic orbit or the line of the Apsides from perigee to apogee eastward by $360^{\circ}$ around the earth once every 8.85 years [25].

viii) Moon's orbital plane precession: The first type of lunar precession is that of the plane of the Moon's orbit. The period of the lunar nodal precession is defined as the time it takes the ascending node to move through $360^{\circ}$ relative to the vernal equinox, the autumnal equinox in Southern Hemisphere of the Earth. It is about 18.61 years and the direction of motion is westward, i.e. in the direction opposite to the Earth's orbit around the Sun if seen from the celestial north. In other words the line of its nodes orbits the Earth on a repeating cycle of 18.61 years (6798 days) and is also called the precession of the lunar nodes [25].

ix) Moon's Axial precession: The rotational axis of the Moon also undergoes precession, once every 18.61 years. Since the Moon's axial tilt is only $1.5^{\circ}$ with respect to the ecliptic (the plane of Earth's orbit around the Sun), this effect is small. 


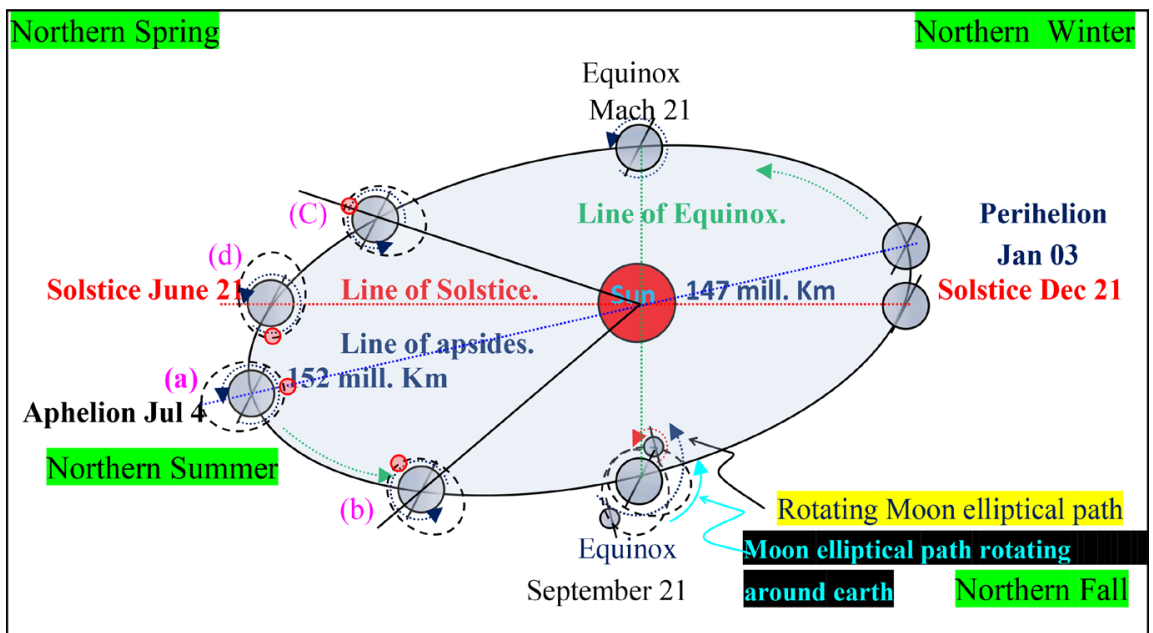

(A)

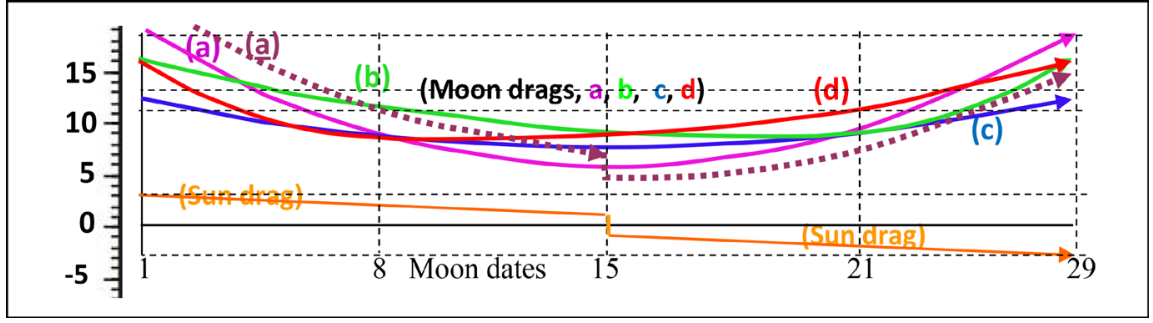

(B)

Figure 4. (A) Elliptical path of Earth around Sun and Moon around Earth are shown above along with four positions of moon perigee with respect to sun due to elongation/angular rotation of its elliptical path; (a) perigee in between sun and earth or in conjunction, (b) perigee at right angle to sun and earth line when going away from sun or first quadrature (c) perigee on side of earth opposite to the sun or at full moon, the elongation is $180^{\circ}$ and it is said to be in opposition (d) perigee at the right angle to sun-earth line while going nearer to sun or $2^{\text {nd }}$ quadrature.

(B) Variation of Sun and moon drags of earth atmospheric air, particularly the Monsoon during a lunar phase cycle in four critical positions of its perigee with respect to the sun. The scale is just supposed for relative analogy or comparison. The approximate or symbolic resultant of (a) and Sun drag is shown as dotted pink curve as (a).

\subsection{Solar and Lunar Eclipses Role}

In the solar or lunar eclipses, the Sun, moon and the Earth are in line and their combined dragging, pulling and particularly shaking activity on the earth is exaggerated and around such events, there may be increase in some abnormal events like earthquake, landslides, tsunamis and volcanic eruptions, both in frequency and intensity over and above the atmospheric exaggerated drags with heavy wind, rainfall and snow storms. The heavy wind may boost wildfire hazards and the recent solar and lunar eclipses may have significant role in extremely exaggerated Australian 2019/2020 and Brazilian 2019 wildfire and their aftermaths, the heavy rainfall, floods, record breaking snow falls, resulting into extreme global hazards throughout the entire world. The above stated events may lead or lag the eclipse, even by a month or more. 


\section{Roles of Celestial Bodies in Major Events}

A few of the main events in the light of the cycles of the above stated celestial bodies are discusses here below.

\subsection{Global Hazards}

Figure 1 shows the number of happenings of various global hazards with the time (and not their intensity, severity or volume) along with the lapses of Venus with time in years, while its vertical location showing its occurrence at time in that year and its scale is shown on right side. Thus location of lapses of Venus in both the axis in this graph is somewhat exact in a year ( $y$-axis scale shown on right side) and also exact on multiple years scale ( $\mathrm{x}$-axis), while all others are sum of events in the whole year. The critical activity of Venus on the earth may be for 19 to 30 days i.e. 9 - 15 days on both sides of a laps. This graph [1] shows the abrupt and persistent growth of almost all the hazards since 1965/70. The roles of all the celestial bodies in this abrupt growth were denied due to mismatching in time of their any activity and incompatible with these in persistency and stature [6] [7]. However, ignoring this abrupt growth, almost more than $60 \%$ of the events of almost all these hazards match with Venus lapses and that may be as a result of its gravity shaking, jolting and particularly its contention in pull with the earth. This shaking and pull contention results in hazardous events as much as is the looseness of earthen item with the earth and when assisted by other favorable conditions. The earth atmosphere is much loosely tied with earth and hence it is much affected through its cyclic drag. Thus wind storms, hurricanes, typhoons, tornadoes, easterlies, monsoons and resulting rains, snowfalls, floods, landslides, avalanches, wildfire and related epidemics are much boosted by this, particularly when solar and lunar location also favor it.

However, in place of all these keen attention is needed towards their main and absolute driver, the continuous heat accumulation on the earth Globe and thus continuous rise in Global temperature due to continuous denial of water availability by IBWT to the IAW part of GAC since $1965 / 70$ which is racing the trains of Global hazards continuously up and up and has left all the other agitators and competitors much behind the scene.

\subsection{Years Frequency of North Atlantic Hurricanes}

For more insight, the graphical presentation of 100 Years Frequency of North Atlantic Hurricanes (NAHHF) as given in [27] was advanced by ten days (approximate travel time from Pakistan to USA) in the [21] to match it with IAW generation stage at RCT deserts, but here it is distributed in more sectors as per their variations for their analysis in more details. Time limits and duration of different sectors is also shown in Figure 5; whereas in Figure 6, their generation stage at RCT location on the elliptical path of Earth around the sun is presented to show the role of variations of gravity and heat radiation as per variation of 
earth distance from the Sun in its annual elliptic movement around the sun, particularly earth velocity and momentum component along the Earth-Sun line (AESL). The characteristic 4 Earth positions, Equinoxes, Aphelion and Perihelion are shown in both the figures. At these points Earth has its speed perpendicular to Earth-Sun line. While going from one of these points to the next, its speed and momentum's AESL component start increasing and after reaching its peak, start decreasing till zero at the next point. These 4 peak points are far away from Equinoxes and almost at symmetric distance; about 30 days on both side of Aphelion and 31 days on both sides of Perihelion. An approximate curve of this variation is plotted/superimposed on Figure 5. Different observation and findings are discussed here bellow.

\subsubsection{Peak Rise and Fall Sectors}

From Figure 5, the peak rise is of 42 and peak landing is of 63 days. Both these numbers are divisible by seven. Thus total peak duration is of 105 days [21]. Both these have 3 steps, each almost of 14 days in rise and of 21 days in fall, again both divisible by seven. Each step, both in rise and fall have nearly $5-7$ sub-steps with rising trend in rise and falling trend in fall. This seems to be related with lunar 4 weeks of varying activity.

\subsubsection{Immediate Coverings of Peak Rise and Fall Sectors}

The immediate end covers are both 40 days each. This means that coastal winds in their successful opposition of westward rolling of IAW are for 40 days each.

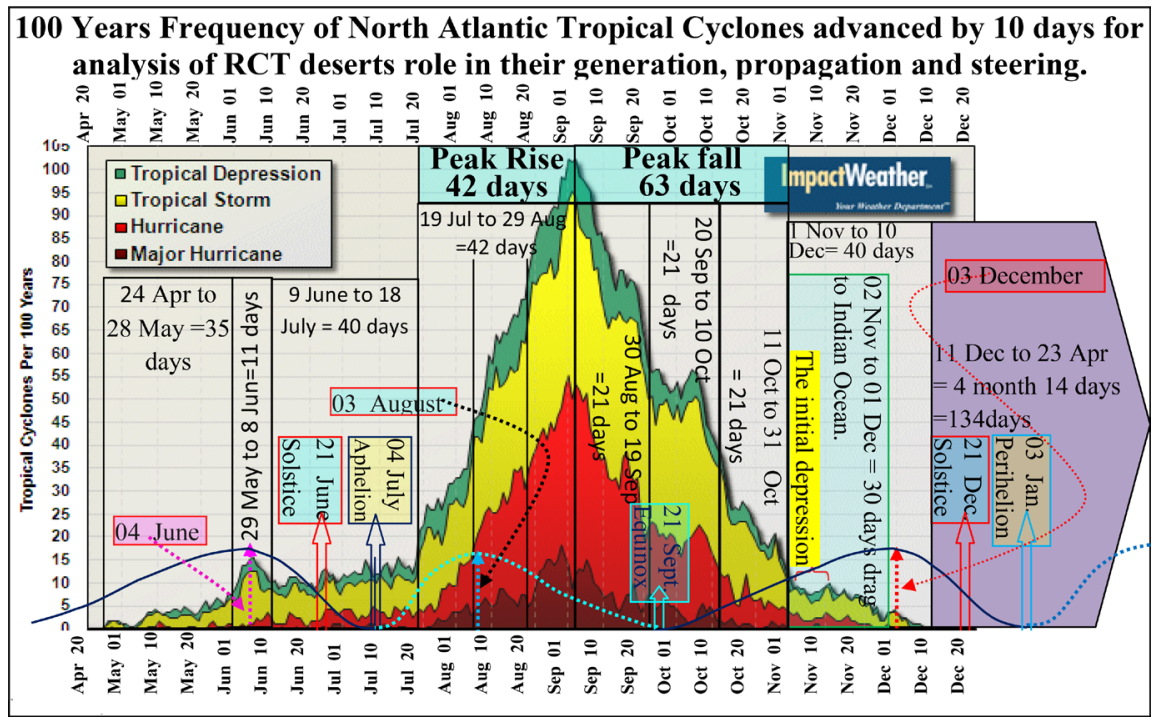

Figure 5. The 100 year frequencies of North Atlantic Major and normal Hurricane, tropical storms and depressions [27] advanced by 10 days for analysis of its correlations with their initiation location parameters. It is divided in various sectors as per its status and superimposed the locations of June and December Solstices, September Equinox, July Aphelion and Jan Perihelion, etc. and land to sea breeze drag of air wheels to Indian Ocean. Also variation of Earth velocity and momentum component along the Earth-Sun line, showing their peak and minimum location at 4 June, 4 July, 3 Aug, 21 Sep, 3 Dec and 3 Jan, etc. 
These eras (Figure 5) also show off and on IAWs slipping and running away on their normal track to Atlantic Ocean from the grip of coastal SLB or LSB winds when these are a bit loose by any reason. The approximate rising and falling slops of hurricanes frequency curves in these eras indicate the agitating temperature rise and fall well closely supported by the variation of its pull due to decreasing and increasing distance between sun and the earth (Figure 5, Figure 6). This also indicates the NAH close association with RCT deserts generated IAWs.

\subsubsection{Far End of Preceding Peak Rise}

This has two distinct sections. The first one is of 35 days showing the IAW generation activity startup by $24^{\text {th }}$ April, immediately after the start of elevated Sun radiations. There is again, off and on westward rolling of IAW in moderate temperature zone of spring season before the start of SLB. As per winter remains of cold environment, IAW generation in this era is quite slow and off and on without any SLB obstruction, as that has not started yet and this carries on increasing slowly as per temperature rise dictations.

\subsubsection{Abnormal Jump in Frequency Graph}

At the end of previous section, the SLB starts matching resistance with a bit sever sun radiations conditions since $29^{\text {th }}$ May. This mutual matching is some time breached by the delay of northeastward SLB by any reason, may that be lunar early dates or every eighth year of Venus cycle or its $4^{\text {th }} / 5^{\text {th }}$ year mid cycle or both with the solar peak resistance to SLB and maximum westward pull to IAWs and thus it results westward atmospheric drag in place of northeastward SLB.

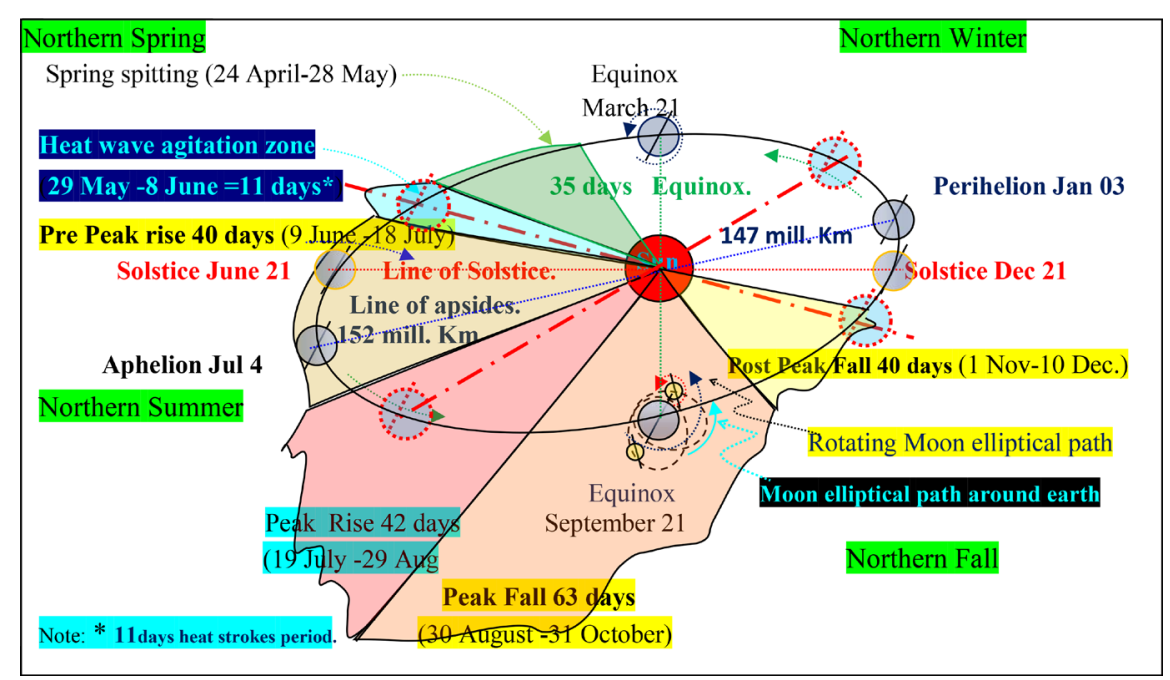

Figure 6. Elliptical path of Earth around Sun and Moon around the Earth, both axial and elliptical rotations along with rotations of Moon in elliptical path around Earth, all counterclockwise when seen from North Pole star. The initiation stages of NAH, i.e. air wheel generation stages from the 100 years frequency graph of NAH Figure 5 are shown on elliptical path of earth to see the role of its 4 characteristic location shown with earth Globe in blue circles and 4 critical locations shown highlighted by red dotted circles. 2 of first 4 and 3 of $2^{\text {nd }}$ fall in NAH at RCT location. The role of these 5 positions is discussed in the text. 
The roaming of this delay of a few days of SLB is within about 11 days span and results in heat wave in Southern Pakistan and Rajasthan boosting IAW generation on one hand and on the other hand it provides the gap and opens the gate for westwards rolling propagation of generated IAWs. This can be seen in the graph as a prominent abnormality to the preceding and following routines. This is often in every $4^{\text {th }}$ or $5^{\text {th }}$ year and is mostly followed by a north Atlantic storm or hurricane. Its recent example is that of Alma hurricane following the heat wave in Pakistan by the end of May 2019. This again confirms the close association of NAH and RCT deserts generated IAWs. Its occurrence at the interval of 4 - 5 years may be due to Venus lapses 8 years and its midway cycle matching the time zone of this situation. This situation is also repeated exactly on the other side of year around $3^{\text {rd }}$ December and a small jump can be seen in Figure 5 and shown in Figure 6, to elaborate their coherence. The two peaks at $4^{\text {th }}$ June and $3^{\text {rd }}$ December are at 180 degree apart with sun in line, while middle largest peak (3 August) has about $85^{\circ}$ and $95^{\circ}$ with the preceding and receding peaks.

\subsubsection{Follower of Peak Fall Section}

At the end of peak fall the IAWs are dragged by the LSB to south, towards Indian Ocean and this eventually does not appear in 100 years frequency graph of $\mathrm{NAH}$. The off and on slipping of IAWs from this LSB to the Atlantic Ocean are however, present in this graph (Figure 5). The depression at the start of this section and then small rise indicates the small recovery of drag by rising LSB. This LSB and the slippers from it, end by about $10^{\text {th }}$ of December when sun radiation support is dropped by winter grip.

\subsubsection{Aphelion, September Equinox and NAH Frequency Curve}

Out of 4 above stated particular points, Aphelion and September Equinox fall in range of NAHHF activity time zone, the first one in slack rising and $2^{\text {nd }}$ one in peak falling zone. Around both these points, the NAHHF curve is fluctuating for sufficient long while, but has no overall rise or fall. This exactly matches to their zero activity as per AESL speed/momentum curve.

\subsubsection{The 4 AESL Earth Peak Speed/Momentum Points and NAH Frequency Curve}

Out of 4 above stated AESL Earth Peak Speed/Momentum points, 3 fall in the range of NAHHF activity time zone, the end ones in slack rising and falling and middle one in peak rising zone. Both the slack zone points (4 June \& 3 December) boost the NAHHF curve well above their normal trends proportional to their normal stature. The middle one (3 August) is in peak rising zone, and hence boosts the NAHHF curve too much promptly. This pushes the curve from first step at 35 to $2^{\text {nd }}$ step at 58 (jump $=23$ ), while its jump to $1^{\text {st }}$ step is by 7 and that from $2^{\text {nd }}$ to $3^{\text {rd }}$ steps is only 8 , i.e. both about $1 / 3$ of this middle one. This means that this solar-earth activity has speeded up the peak rising activity too fast, hence the rising activity has gained its full stature in short while of only 42 days. The corresponding activity of 21 September on other side of curve is pro- 
longing the duration at an elevated stage and this contributes much in elongation of falling zone to 63 days. Also first peak to peak AESL momentum curve from 4 June to 3 August is of only 60 days with accordingly small share of 4 July zero or no change activity duration, whereas, second peak to peak AESL momentum curve, 3 August to 3 December is 123 days with accordingly large duration share of September 21 Equinox zero activity or no change within the peak fall zone, elongating it much longer. Both the above stated ideologies or factor contribute in shortening the peak rise duration and promoting elongation of the peak falling sector with strong particular role of earth elliptic path, its Aphelion and September Equinox and its 3 points locations of peak AESL earth speed/momentum on NAHHF and its curve.

\subsubsection{Peak Location Time of NAH Frequency}

Approximately around $29^{\text {th }}$ August is the highest frequency location of IAW generation mainly depending not only on prevailing temperature boosted by sun radiations over and above the already set GHT baseline, within the gap between end of SLB and start of LSB winds, but also on the solar gravity on earth and on IAW generation and propagation speed and particularly on earth AESL momentum as discussed above in sub-Section "3.2.7".

\subsubsection{Durations of Peak NAH Frequency Takeoff and Landing Sections}

To the question, why this fall is so prolonged than the rise, two logical factors are given above in sub-Section 3.2.7 and another was given in [21] that preceding Sea to Land Breeze has an eastward component which opposes the westward movement of IAW till its complete settling down and following Land to Sea Breeze has a westward component flowing in phase to IAW rolling direction, the preceding one in opposition and the follower one in support as shown in Figure 7 and this reduces the rise and elongates the fall by 10.5 days each as given below.

$$
\begin{aligned}
& 42+x=63-x \\
& \text { Or } 2 x=63-42=21 \\
& \text { Or } x=10.5 \text { days }
\end{aligned}
$$

Also, the three sub steps' days are

$$
\begin{aligned}
& 14+x=21-x \\
& \text { Or } 2 x=21-14=7 \\
& \text { Or } x=3.5 \text { days }
\end{aligned}
$$

This means, that both rise and fall were to be of 52.5 days, but resisting wind reduced it to 42 days activity in rise and in fall, the supporting wind dragged it further to 63 days.

Of all these 3 logics, first 2 have more solid ground and it seems that all the 3 are working together in phase and contributing jointly to this end. This further confirms the direct relationship of NAH with RCT deserts generated IAW. 


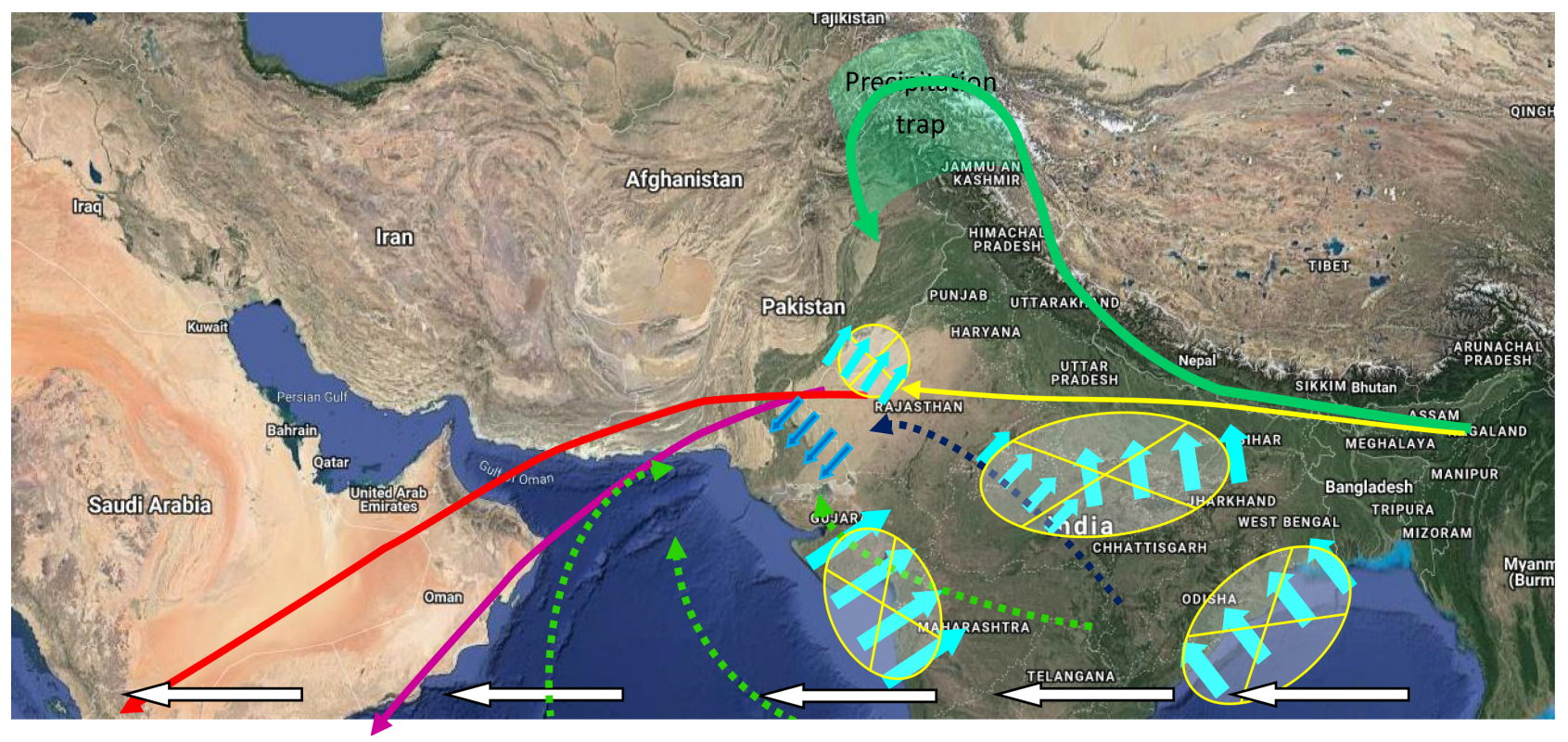

Figure 7. Yellow line, the re-established track Monsoons are pusher of Rajasthan generated air wheels, while green dotted lines representing Indian Ocean wind blasts, slow down their speed except the one represented by blue dotted line. These blasts (green) result in fizzling out of hurricanes before their landfall in USA, while those with boasted speed by Monsoons may result into deep penetration in USA with extreme damages and huge losses. The resulting Indian rainfalls has minor effect reducing heat contents and temperature and air wheels energy except the rain and dense clouds on Rajasthan which will obstruct the air wheel generation for a few days, an unwanted event in view of extreme Global heat dissipation demands. However, rainfall in Chulistan, Thar, Sindh and Southern Baluchistan and the optimum irrigation supply is most fruitful both for GHT control and NAH family moderation.

\subsubsection{Sun Role in NAH Peak Frequency and Intensity}

Figure 6 shows the variation of earth distance from the sun. Along with the sun indirect and direct roles discussed above, the solar gravitation also has prominent role varying as per earth-sun distance variation and its orientations with the direction of earth annual motion. This role is three folds, one direct on the IAW and NAH boosting their speed during their whole journey, $2^{\text {nd }}$ through their push by its accordingly elevated Indian monsoons and $3^{\text {rd }}$ through their continuous push by accordingly elevated easterlies, all the 3 following sine curve, over and above the role of environmental temperature affected too by this distance variations too. This activity also seems to be logical and forceful along with those stated in Section 3.2.7, 3.2.8 and 3.2.9 above and all the four are mutually monotonically in phase.

The June Solstice, July Aphelion and September Equinox in Figure 5 and Figure 6 are miles stones in the earth elliptic motion and are shown to indicate the location of different steps of 100 years frequency graph of NAH. Except the Solstice, the other do have significant role in the issue under discussion as pointed out above. The 4 AESL points have an important role too and as per their significance must also be presented along other six points on the earth elliptic path around the sun.

The growth of GHT will boost and widen the brutality of all the above steps of $\mathrm{NAH}$ and Indian monsoon and all their aftermaths too. The very first targets of 
the above stated activities are Southern Indian subcontinent with both widened and elevated heat waves and USA, Europe and Caribbean countries with severer hurricanes and elevated heat waves too with a bit less for the rest of the World.

\subsection{Venus Role in NAH and Monsoons}

The Venus overtakes the Earth in its orbital movement from behind and passes by it in opposite direction of the Earth surface daily movement about its polar axis. This increases the drag of atmospheric air against the earth daily rotation due to its gravitational pull and hence the westward air speed, turbulence and quantity of monsoons flow and resulting a bit heavy rainfall, furious hurricanes can be observed from their records and also from its indicators, the Pakistani rivers floods flow in Figure 8 and bar chart of major NAH Figure 9, when the Venus passes by the Earth. This Venus cyclic activity is quite evident from general conformity of the flow of various rivers as given by [28] (Figure 8) with repetitions as per Table 1 by 1, 3, 5 lapses (i.e. 2, 5, 8 years) or 2, 3, 5 (i.e. 3, 5, 8 years) or 2, 4, 5 (i.e. 3, 6, 8 years) as the active years unless otherwise agitated by any other supporting or opposing event and lapses lagging or leading out of the season. The major NAH show $96.6 \%$ matching response with Venus/Earth lapses (as stated in caption of Figure 9), surly through its boosting of Indian Monsoons and this confirms the behavior of Venus on Indian Monsoons of earth Globe at least by $80 \%$ - 90\%. The 2004 Transit has continuously increasing effect on NAH frequency in years 2002, 2003, 2004, 2005 showing their increasing activity with their increasing alignment being on side approaching the sun, thus the pull of the two aliening in phase, while in 2012, it has continuously decreasing trend in 2010, 2011, 2012, and 2013 (Figure 9) showing their decreasing activity being on receding side, thus decreasing the alignment and hence the drag. The overall difference in the frequency stature of NAH in two cases of rise and fall is almost equal and this also shows the difference in their activity as equal and opposite. The high mutual approaching speed of earth surface and Venus having opposite direction has higher activity than their mutual retreat again having opposite direction. It may also be observed from the comparison of Venus behavior on monsoons and NAH as given above that Venus action is twice or thrice on NAH than on monsoon, one indirectly through monsoon thrust and the other directly on NAH during its various stages of propagation, all mainly in form of their drag. For more detail of their activity refer to the caption of Figure 9. The systematic lapses cycle of Venus cannot be responsible for continuous abrupt change in Global Hazards after 1965 (Figure 1). It however, is supporter/booster of excitation of many of them directly or indirectly.

The season concerned here in this discussion is that of major IAWs generation $\left(19^{\text {th }}\right.$ July $-31^{\text {th }}$ October $\left.=\right) 105$ days and its coverings stated above i.e. total active period (24 April to $10 \mathrm{Dec}=$ ) 231 days. Venus mid-cycle at about $4 / 5$ years is also active if its predecessor is at leading end of the season. Accordingly it may occur at about 4 or 5 years with approximately similar role. 


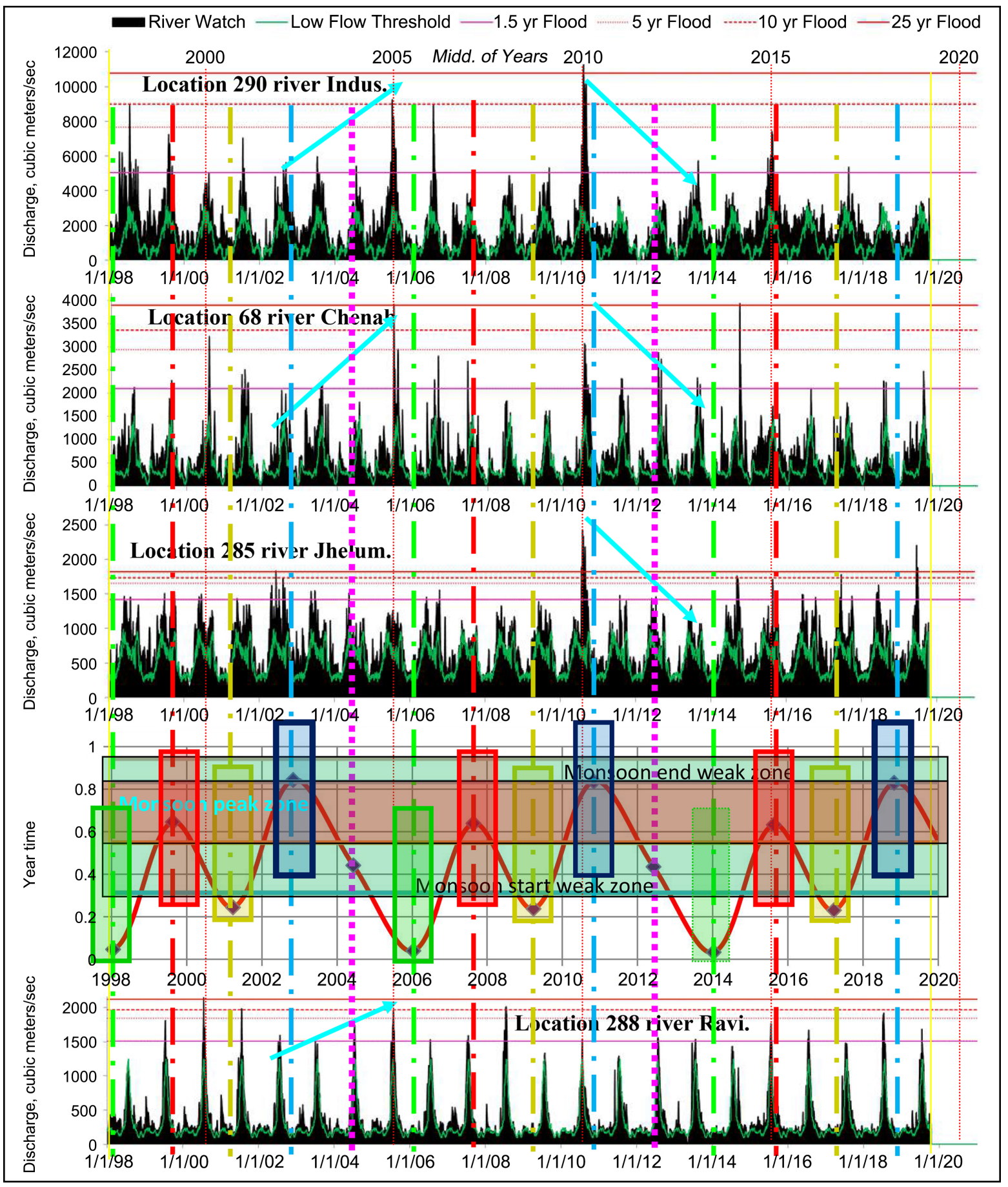

Figure 8. Above are the monsoons intensity indicative Flows of Indus rivers system recorded by [28] and Venus lapses to see their correlation. The repetition of peak floods in general after $(2,5,8) ;(3,5,8) ;(4,6,8)$ years combination as can be seen above matching with the Venus lapses in Monsoons. The lapses (highlighted Blue) of September/October have crossed monsoon almost just before the lapse, thus their preceding side is active fully, while those around July/August (highlighted red) have both sides in active zone and their activity practically matching accordingly. Also those around April/May (highlighted yellowish Green) are bit less active (60/70 \%) with the follower monsoon, while those around January/February (highlighted Green) seem to be 50/60\% promoting the follower season. Excluding the 3 highlighted Green, out of nine lapses in monsoon of 21 years, only one (2013) is not prominently active. The Venus transits at 2004 and 2012 are highlighted with pink dotted line have 4 years rising and 4 years falling trend respectively indicated by cyan arrows except that of Jhelum in year-04 perhaps flattened by upstream dam flow storage/regulation and Ravi in year-12. 


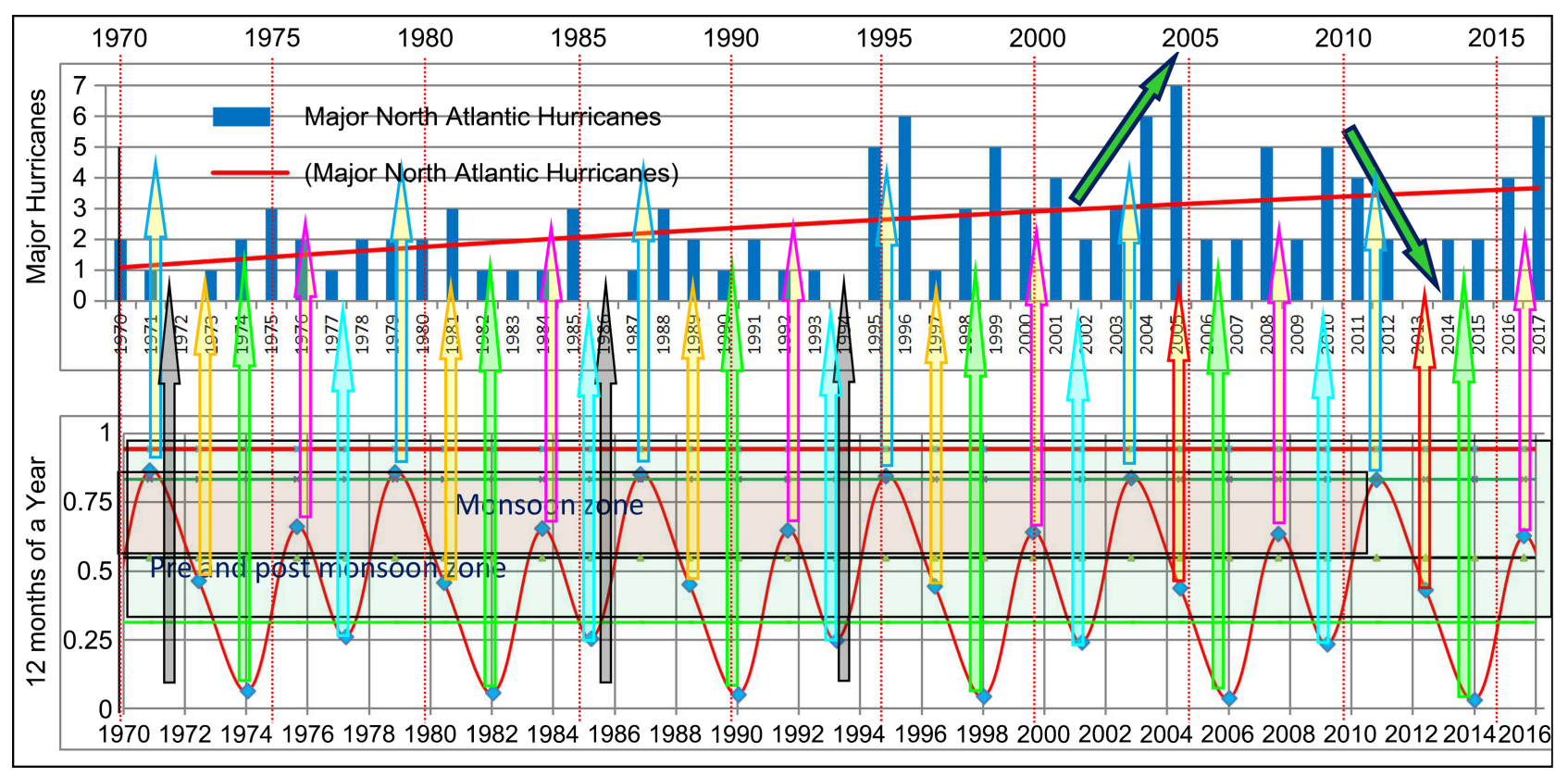

Figure 9. Matching of Venus lapses and NAH frequencies are presented above. Lapses are versus time bounded while NAH are summed for each year. Out of 29 lapses; upper 18 fall in Monsoon season, of Peak frequency of Major NAH (shown yellow) have prominent peak, while one of 2012 do not show this, while the 6 (shown green) and 5 (shown cyan) are preceding monsoon are all active. It means that $96.6 \%$ Venus lapses are actively boosting NAH, both in intensities and frequencies through boosting the activity of Indian monsoon and directly on rest of their track. The transits at 2004 \& 2012 highlighted with red boundary line arrows have 4 years rising and 4 years falling trends respectively indicated by green arrows. The first rising and $2^{\text {nd }}$ falling frequencies are due to the approaching and departing speed increasing the alignment of sun and Venus gravitational pulls and reverse in the $2^{\text {nd }}$ case, with equal rising and falling spans and this includes vacant 2013 in sequence. The other three gaps years indicated by black arrows are in between the 2 consecutive lapses falling in the peak monsoon zone.

Thus approximate $4 / 5$ years' cycle of intense monsoon nearly correspond with Venus 8 years half and full cycle.

In the critical 105 days, IAW generation duration at RCT or the monsoons, the Venus will take only 65 days to cross this if the two are in phase and less than that if they are out of phase. In its total (24 April to 10 Dec. =) 231 days, IAW generation active period of RCT activities, the Venus will take 143 days to cross this if the two are in phase and less than that if they are out of phase. Along with the 1.6 year cycle, a Venus elliptical rotation plane procession makes variations in its action on the two hemispheres of the earth. The 2004 transit was more active on Northern, while 2012 was more active on Southern Hemisphere. This also may have some role in the frequency trend of the two sets of NAH stated above.

\subsection{Solar and Lunar Role}

Both Sun and the moon have gravitational pull and hence the drags force against the earth daily rotation on both water and the atmospheric air, not rigidly tied with the earth crust. Water is, however, somewhat confined within the oceans and lakes boundaries and thus experiences 24 hours cyclic four tides, two high and two low depending upon the resultant pull of sun and the moon, varying 
due to their mutual locations with respect to earth within $29.5(=14 \times 2$ or $7 \times 4)$ days cycle of the moon. The 7, 14, 21 and 29.5 day locations depending drag variation might have role in 42, 63 and 35 days sector formations in 100 years frequency graph of NAH (Figure 5).

\subsubsection{Solar and Lunar Elliptical Orbit Role}

The atmospheric air is more loosely connected with the earth and has almost no confining barriers, hence undergoes the drags more strongly and vastly than water over the entire Globe. With respect to monthly rotation of moon, drags due to moon and sun are in phase in first two weeks (referred to in No. iv above in Section 2.3) and in opposite phase in last two weeks, shown symbolically in Figure 4(B). The drag force on atmosphere in front of moon due to both moon and sun carries on decreasing till $14^{\text {th }}$ day of moon due to decreasing sun drag and then the sun drag become opposite with increasing trend and thus net carries on decreasing as per relative location of moon with respect to sun till the new moon where it jumps to maximum again by becoming both in-phase. The sun drag of atmosphere varies too as per earth distance from the sun depending upon Earth own locations on its elliptical path around sun, but its variations within a month are very small. The moon drag during the month varies as per its distance from the earth depending upon its location on lunar elliptic path, which also vary in cycle of 18.61 years. The prominent positions of it are shown as (a), (b), (c) and (d) in Figure 4(A), with drag trend shown in Figure 4(B), but not appreciable in a month or two. The drag due to moon is more than sun being close to the earth. This drag is maximum at the new moon assisted by decreasing sun drag and carries on decreasing till dark moon resisted by increasing sun drag after $14^{\text {th }}$ day of moon (Figure $4(\mathrm{~A})$, Figure $4(\mathrm{~B})$ ) and these affect the IAWs, monsoons and NAH accordingly. The symbolic resultant drag is shown by dotted curve (a) as the sum of lunar (a) and the Sun drags.

\subsubsection{Role of Perigee Location with Respect to Earth-Sun Line}

In the four extreme locations of perigee shown in Figure 4(A), the location (a) is the maximum for atmospheric drag and (c) is relatively least.

\subsubsection{Role of Precessions of Moon's Orbital Plane and Apsidal}

The 18.61 years cycle of Moon's Orbital Plane precession provide the Opportunity to the 8.85 years cyclic apsidal precession to be in most excited situation for atmospheric drag at its every alternate 8.85 years cycle in the situation (a) of No. v above (Section 2.3) with matching format No. vii and No. viii above and least excited on the next. Thus, the atmospheric drag will be in most calm and quiet situation in between the two most excited and turbulent ones. The practical confirmation can be seen in its indicators, the graphs (Figure 10) of most critical floods in Pakistan recoded by Federal Floods Commission, Ministry of Water and Power, Government of Pakistan [29] [30] [31] [32]. This figure shows 3 cycles of approximately 18.5 years having 4 clusters of alternately 3 - 4 and 5 - 6 
years heavy floods flows and in between the 2 such clusters $13-14$ years alternately moderate and low flow zones. These are surely directed by combinations of 18.6 years and 8.85 years lunar cycles with perhaps leaning towards Northern and Southern Earth Hemispheres. Even the two most excited cycles after 18.5 years period do not exactly match. From this figure, it appears that $3-4$ and 5 6 years clusters occur alternately and about $13-14$ years span between the two with $4 / 5$ years minimum flow at the center is again cyclic. This $13-14$ years span follower of 5 - 6 years heavy floods flow is of moderate floods, while the follower of 3 - 4 years cluster is of minimum or no floods flow and accordingly its central 4 - 5 years critically low flow. Thus, it seems that at least it has 37 years cycle. However, from mutual progression of 18.61 and 8.85 years cycles, the above stated excited situation will vary in a cycle of $\mathrm{x} \approx 10$ and so will do its directed situation as estimated below.

$$
\begin{gathered}
18.61 \mathrm{x}=8.85(2 \mathrm{x}+1) \\
\text { Or }(18.61-17.7) \mathrm{x}=8.85 \\
\text { Or } \mathrm{x}=8.85 / 0.91=9.73 \approx 10
\end{gathered}
$$

This means that period of this cycle will be approximately $8.85 \times 9.73 \approx 86$ years.

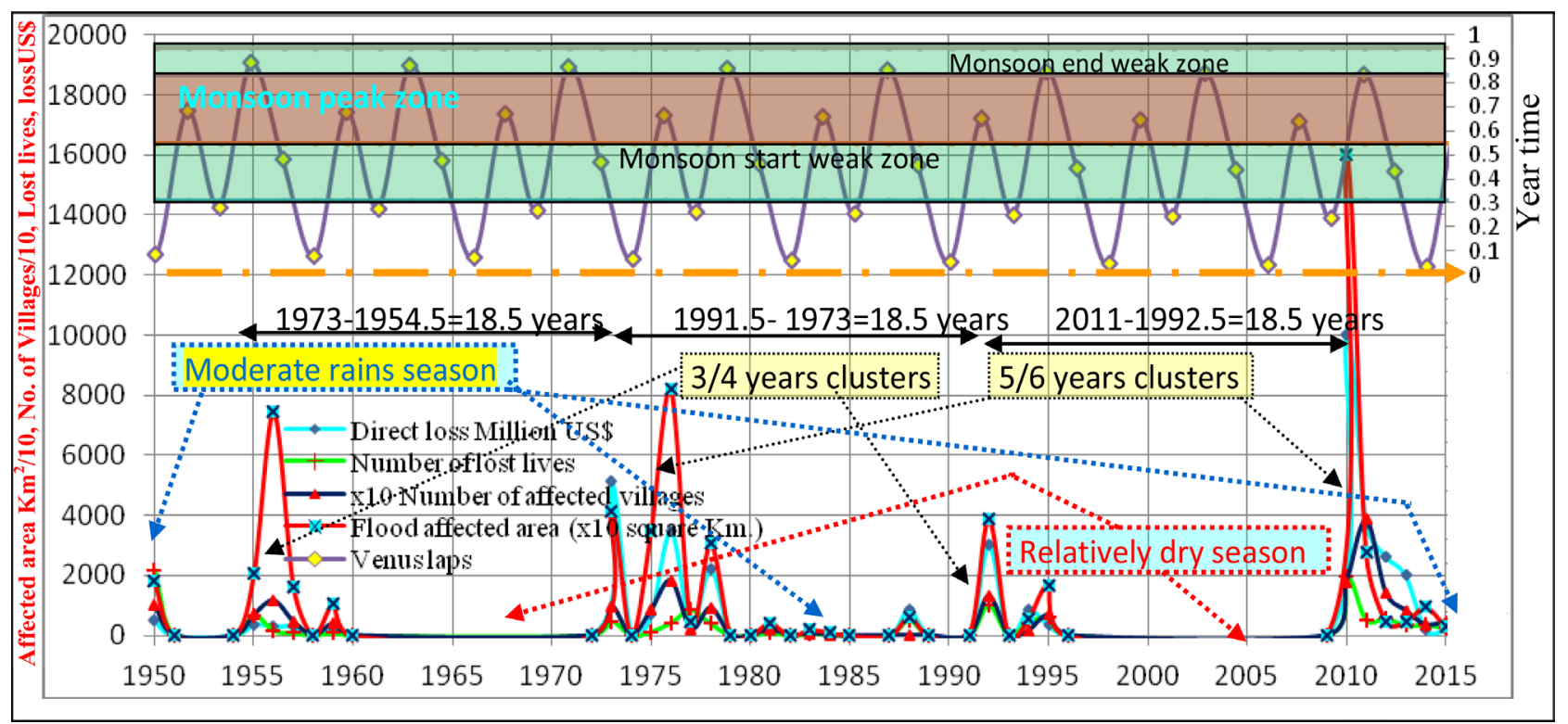

Figure 10. The above graphs shows the trend and frequency of floods in Pakistan. The 18.5 years repetition frequency, with perhaps alternate $3-4$ and 5 - 6 years cluster/bunch of extreme floods and $13-14$ years bunch of normal or minimum rivers flows is quite evident. These 13 - 14 years may have about 4 year minimum river flow or major dry season in the middle and 4 5 year moderate floods around the dry season. This seems to be patched with lunar nodal procession cycle of 18.61 years when along with lunar apsidal procession cycle of 8.85 years, moon is closest to the earth's northern hemisphere in its every second cycle. This accordingly dictated intensity of small and large clusters of the heavy raining years. The alternate dry and rainy zones in these may have also cyclic routine. In the next and previous cycles it will be on the southern side and hence comparatively dry season on the northern side. As is evident from graphs, Venus lapses has minute role as compared to moon dictated sizable flood flow. 


\subsubsection{Lunar Response in NAH 100 Years Frequency}

The lunar joint cycle of Orbital Plane and every $2^{\text {nd }}$ Apsidal Precessions vii with (a) formation superimpose its affects on all the excited duration of NAH. The 100 years frequency graph (Figure 5) of NAH is the result of 5/6 above stated 18.61 and 8.85 years joint cycle activities. The 3 steps of 14 days each in peak rise further seems to corresponds to the first two weeks of maximum drag after new moon assisted by rising temperature and increasing solar pull/drag due to decreasing Earth distance from Sun after passing the Aphelion (Figure 4(A)). The 3 steps of 21 days each in peak fall further seems to corresponds to the first three weeks of maximum drag after the new moon. However, it does not have any solid reasoning for its confirmation. The decreasing earth-Sun distance and hence increasing gravity along with earth elliptical speed may have positive role in this elongation of falling activity of NAH.

The above stated lunar orbital plane precession takes:

$18.61 \times 105 / 365.24=5.35$ years to cross the NAH peak duration.

Here, $42+63=105$ days is the peak duration (Figure 5).

While, Apsidal Precessions cycle takes:

$8.85 \times 105 / 365.24=2.54$ years to cross peak duration (Figure 5, Figure 6).

Thus critical excitation remains for 3 - 4 years if 18.61 and 8.85 years cycles are concurrently matching and $5-6$ years cluster if mismatching. These years are thus with extraordinary rainfall, if not avoided by any other event. The first one is small and both can be physically seen in the graph Figure 10. As stated above, the 18.61 years cycle seems to have two extreme high at its end. In between two extreme high, there are two moderate floods of 3 - 4 years cluster duration around one $3-4$ year peak drought season. The two extreme high at the two ends of 18.61 years cycle seems to have again alternate larger (5 - 6 years) and smaller (3 - 4 years) high flow clusters (Figure 10). Thus lunar cyclic activities on earth is of period 7, 14, 29.5 day and 2.54 years prominent in 8.85 years cycle, 5.35 critical in 18.61 years cycle along with $8.85,18.61,37$ and 86 years. Figure 10 and Figure 11 [32] [33] [34] shows 37 years cycle; 4 years peak rain, 14.5 years dry season, particularly central 3 - 4 years, then 5 - 6 years heavy peak rains, then 13 - 14 years moderate rains matching the lunar 37 years combined cycle of two 18.6 years and four 8.85 years cycles with 2.54 years corresponding to 3 - 4 and 5.36 to 5 - 6 years of Figure 10. Thus it is quite evident that Lunar Apsidal and Nodal Precessions Cycles Drive Floods flow through monsoons in Pakistan and for 37 years cycle, Pakistan would have to manage 31 - 40 years flow storage and its release regulation.

Kashmir Valley Recoded Heavy Rainfall: From the available literature and articles present on the Internet, it is observed that the Srinagar valley (Jhelum River) witnessed significant flooding during 879 AD, 1841, 1893, 1903, 1929, 1948, 1950, 1957, 1959, 1992, 1996, 2002, 2006, 2010 and 2014 [35] [36]. Excluding the $879 \mathrm{AD}$ record and adding the recent rainfall of 2018 , the data is tabulated for analysis in Table 2 below. The time span between consecutive record years is tabulated in next columns and in the next, it is tabulated as multiple of 4 
and in the next column only multiple is tabulated. Now see that out of 14 values, 9 are whole numbers and only 5 are fractions and that too are with 0.5 fractions. It means that $64 \%$ heavy rain fall occurring follow 4 years cycle and only $36 \%$ differs from this and that too by half of 4 , that is to the full and half of 8 year Venus cycle. And then in next 2 column are tabulated this in approximate multiple of 18.6 and 8.85 . The approximate whole numbers in these two columns show their correlation with lunar cycles of 18.6 and 8.85 years. These occurrences and floods record of ministry of water and Power of Pakistan are plotted along with Venus lapses (Figure 12). This figure shows Floods record locking

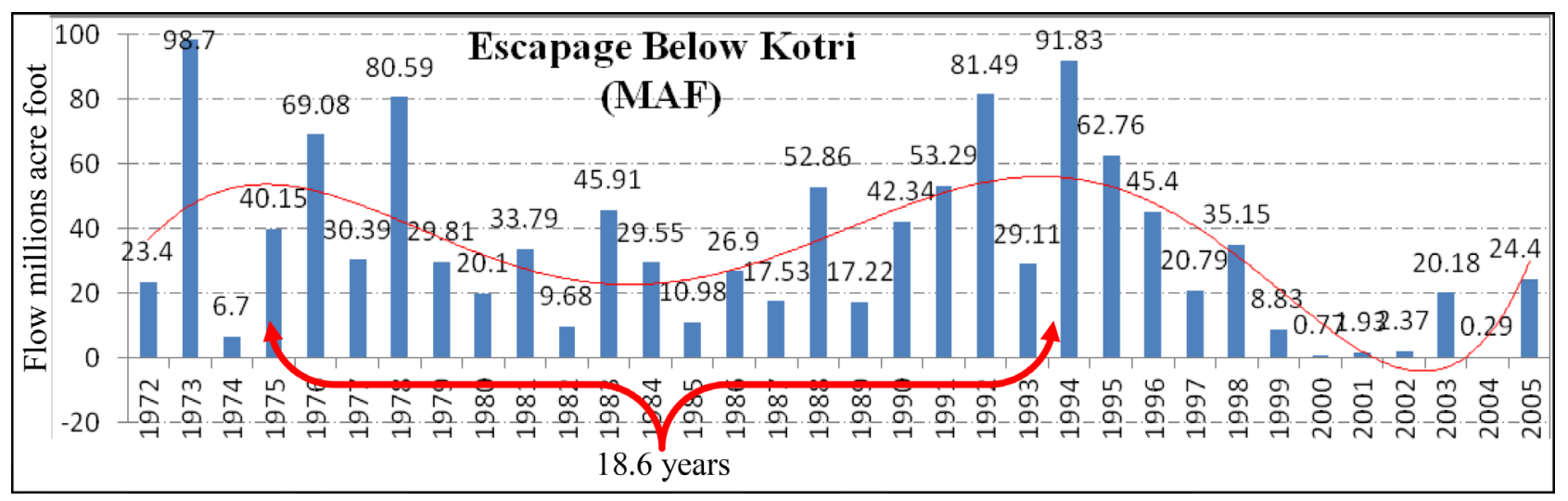

Figure 11. The above is year vise flow to Arabian Sea from Kotri barrage at tail $(32,33,34)$. Polynomial trend (red) shows its flow trend. This is another evidence of the paradigm elaborated in Figure 10 above. This lunar directed period of 18.6 years is of higher flow, while the next is of lowest flow. At least $2 / 3$ of the next will be in the danger zone, hence over the years or multi-decade storage and flow regulation requirement is $=18.6+18.6 \times 2 / 3=31$ years or $18.6+9.3+2(4$ critical years at center $)=30$. The average flow per year is $34.25 \mathrm{MAF}$.

Table 2. Analysis of heavy rainfall in Kashmir valley.

\begin{tabular}{|c|c|c|c|c|c|c|}
\hline S/No. & $\begin{array}{c}\text { Heavy Rain } \\
\text { years }\end{array}$ & Time span & $\begin{array}{l}\text { Time span } \\
\text { in of } 4\end{array}$ & $\begin{array}{l}\text { Multiplayer } \\
\text { of } 4\end{array}$ & $\begin{array}{l}\text { Multiplayer of } \\
18.6 \text { or } 18 \text { years }\end{array}$ & $\begin{array}{c}\text { Multiplayer of } \\
8.85 \text { years }\end{array}$ \\
\hline 1 & 1841 & - & - & & & \\
\hline 2 & 1893 & 52 & $13 \times 4$ & 13 & $\approx 4$ & $\approx 6$ \\
\hline 3 & 1903 & 10 & $2.5 \times 4$ & 2.5 & & \\
\hline 4 & 1929 & 26 & $6.5 \times 4$ & 6.5 & $\approx 1+8$ years & $\approx 3$ \\
\hline 5 & 1948 & 19 & $5 \times 4$ & 5 & $\approx 1$ & $\approx 2$ \\
\hline 6 & 1950 & 2 & $0.5 \times 4$ & 0.5 & & \\
\hline 7 & 1957 & 7 & $2 \times 4$ & 2 & & \\
\hline 8 & 1959 & 2 & $0.5 \times 4$ & 0.5 & & \\
\hline 9 & 1992 & 33 & $8 \times 4$ & 8 & $\approx 2$ & $\approx 4$ \\
\hline 10 & 1996 & 4 & $1 \times 4$ & 1 & & \\
\hline 11 & 2002 & 6 & $1.5 \times 4$ & 1.5 & & \\
\hline 12 & 2006 & 4 & $1 \times 4$ & 1 & & \\
\hline 13 & 2010 & 4 & $1 \times 4$ & 1 & & \\
\hline 14 & 2014 & 4 & $1 \times 4$ & 1 & & \\
\hline 15 & 2018 & 4 & $1 \times 4$ & 1 & & \\
\hline
\end{tabular}




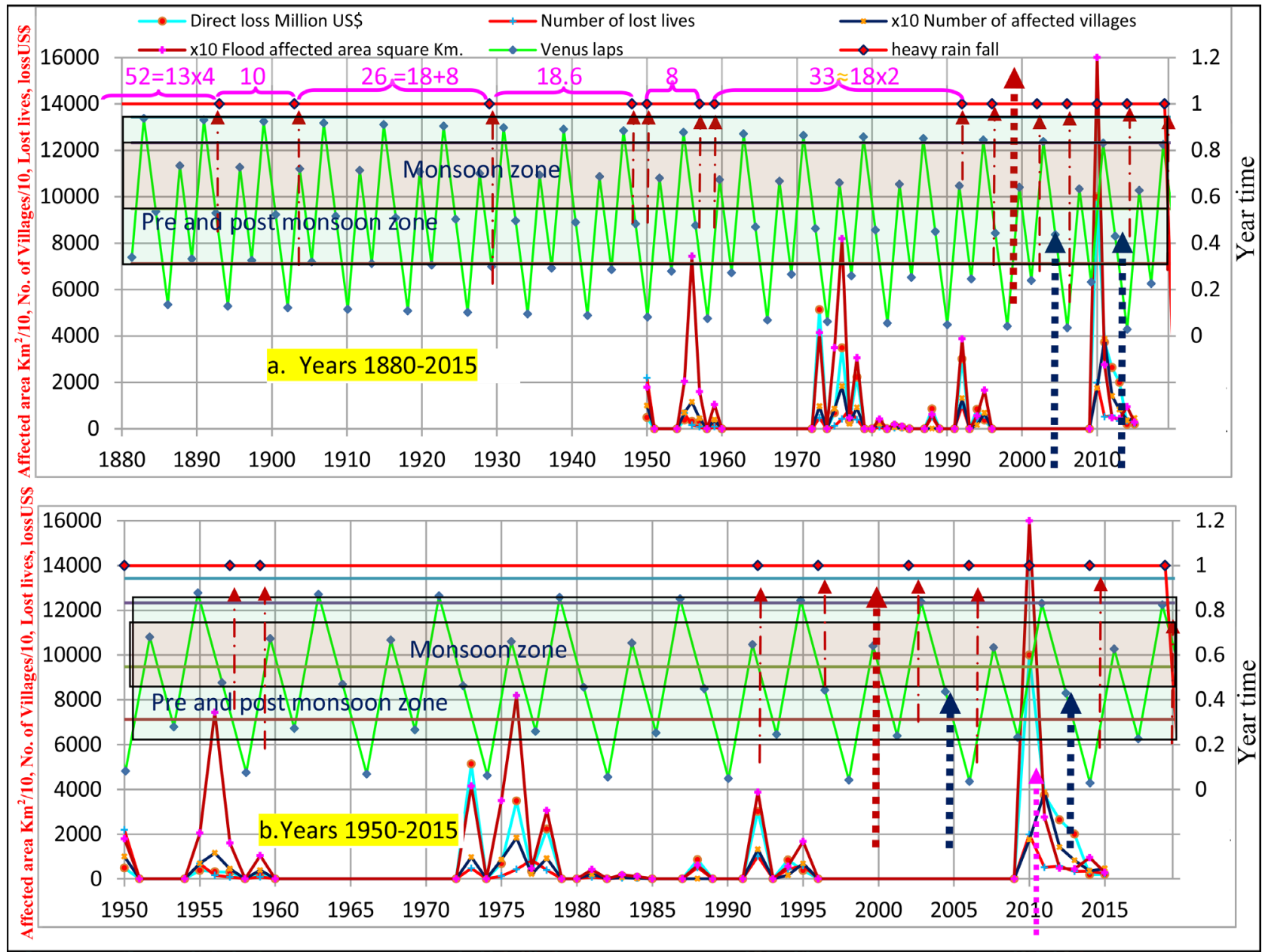

Figure 12. Time (upper a. 1880-2015 and lower zoomed b. 1950-2015) versus plot of Kashmir Valley heavy rain falls, extraordinary floods in Pakistan and Venus lapses is shown above. Extreme Floods seems to be more responsive to Lunar 18.6 and 8.85 years cycles with matching combination at 1955 and 1992 smaller clusters and 1975 and 2010 prolonged clusters due to their mismatching. These clusters are the years when moon during its joint Apsidal and nodes precessions crosses the monsoon season in 3 - 4 or 5 - 6 years causing heavy rains. The Kashmir Valley heavy rainfall shows complete locking of rain fall with Venus lapses, mind that lapses in these graphs are time bounded, while rainfalls and floods are plotted against the year's end. Moreover, the momentum gained by the dragged atmosphere even if the Venus lapse has preceded the monsoon will positively boost the rainfalls activity. Also this locking is within the limits of lunar forcing. The heavy rains in year 1999 (brown vertical arrow) is not of stature to appear in the graph, while 2010 (pink vertical arrow) is prominent and falls in 5/6 years heavy rains cluster. Lunar effect dominates 2004 and 2012 Venus Transits (blue vertical arrow) activity.

with lunar cycles more rigidly and less with Venus, while almost all values of Table 2 show their locking with Venus half of 8 years cycle within the bindings and limitations of lunar cycles. Year 1999 pointed out may be for new 4 years cycle base. The Era before 1993 shows compromise between 4, 8 years Venus and 18.6 and 8.8 years lunar cycles as shown by pink gaps, while thereafter, their matching status is boosting the rain fall. How long and how much this compromise persists is a field for further research? The Transits of Venus in 2004 and 2012 pointed out by dark blue arrows have shown no extraordinary activity here. These observations somewhat cyclic perhaps might have been forced by systematically cyclic combination of changing celestial body's mutual location and 
orientations. Those non cyclic may be the aftermath of some accidentally occurring events likes volcanic eruptions, huge wildfires, large use of explosives in warfare, nuclear tests (1944 nuclear bombing of Japan) or huge obstruction in Global heat transport to troposphere by IBWT through huge obstruction in water evaporation and precipitation cycle, etc. [37].

\section{Findings and Results}

1) Nature is providing the opportunities for welfare of mankind and through hazards and catastrophes forcing human beings to avail these opportunities and do not only say "we die of drowning when there is rain and die of thirst when there is no rain" (saying of a Pakistani Chief Minister). The Natural guidance is that construct the dam to store the water in it so that it may not drown you and then release this storage systematically as per need dividing it over the non-raining period so that you may not die of thrust.

2) The most of the activities of these celestial bodies are beneficial and vital for restoration of ecosystems on the earth Globe, provide opportunities for welfare and development, if these are not disturbed, damaged or misused by unscientific, illogical and unnatural (UIU) move like implementation of tragic IBWT and tragic recommendations of World Bank report on developments of Water and Power Resources of (then) West Pakistan [38] resulting into continuous disasters, huge financial losses, wastage of resources and promotion of extreme obstructions and hurdles in their future easy availability in place of benefitting from these resources.

3) Venus has maximum 143 days with critical maximum 65 days out of 583.9236 days cyclic drag of atmosphere and has role in most of the hazards as can be seen by analysis of data of Figure 1 .

4) The Moon various cyclic operations, the major and prominent based upon its daily, weekly, monthly, 8.85, 18.61, 37 and 86 year periods on atmosphere, monsoon, wind and snow storms, hurricanes, landslides, earthquakes, tsunamis and volcanic eruption etc may become violent in some UIU scenarios.

5) Sun has numbers of activities on earth for welfare of its inhabitants and steering number of events, if UIU scenario is not hurled in its routine, like nuclear tests, warfare, wildfires, IBWT, unscientific and illogical development recommendations of Water and Power Resources of Pakistan.

6) Moon 18.61 year cycle has alternate 5 - 6 (a) and 3 - 4 (b) years heavy monsoons cluster and in between the two, is again an alternate situation; $\boldsymbol{a}$ to $\boldsymbol{b}$ is moderate flooding or flow, while $\boldsymbol{b}$ to $\boldsymbol{a}$ is relatively dry or low flow leading to 37 year cycle of earth climate. This is guidance to Pakistan for planning its system to regulate irrigation supply over an 18.6 to 37 years span through forehand well planed surface water dam storage and also underground aquifer recharging when surface water is available and preparation for its usage when its demand arises.

7) These clusters are the years when moon during its joint Apsidal and nodes precessions crosses the monsoon season in $3-4$ or $5-6$ years causing heavy rains. 
8) Venus is enforcing four year cycle on heavy rain at $64 \%$ probability and moon is forcing 18.5 year cycle on it.

9) Indian Monsoons and NAH frequencies are mainly directed by solar heat on GHT baseline and Earth rotation but also by variation of component of earth speed and momentum in the direction of sun-earth line changing with earth location on its elliptical path around the sun.

10) NAH 100 years' frequencies graph has been shaped jointly by sun, earth, moon, Venus activities, particularly by earth movement in elliptical path, SLB and LSB.

11) The 2 end peaks ( $4^{\text {th }}$ June and $3^{\text {rd }}$ December) of 100 years frequency graph of NAH are boosted and locked with the points of peak earth AESL momentum.

12) The $3^{\text {rd }}$ August point of peak earth AESL momentum is booster of swift peak rise and thus reducer of peak rise sector duration.

13) The $4^{\text {th }}$ July and $21^{\text {st }}$ September are non active and hence sustains the statuesque and thus later one having large time share prolongs the NAH peak falling/landing section.

14) The continuous heat accumulation on the earth Globe and thus continuous rise in Global temperature due to continuous denial of water availability by IBWT to the IAW part of GAC since 1965/70 is racing the trains of Global hazards continuously up and up and has left all the other agitators/contributes/ competitors much behind the scene.

15) Warnings: Unless immediate GHT optimum blocking measure are taken as recommended in [21], this issue is going to build up a terrible scenario beyond all imagination, crossing all boundaries and limits, overruling all rules and regulations, perishing all barriers, hurdles and bindings, setting all new horrible game parameters and paradigms, resulting into extreme calamities and catastrophes over the entire Globe like its recent mini, rather tiny 2020 Europe attack version.

\section{Recommendations}

1) UIU activities must be avoided.

2) Any UIU activity already gone for must be reversed immediately with safety measures.

3) Sun, Moon and Venus roles on earth should be studied in detail.

4) Development planning must be made with future vision of roles of these celestial bodies.

5) Pakistan and India should plan and manage their water storage and irrigation with mutual cooperation, understandings and concentrations on 18.6 and 86 years moon cycles, surly without treacherous tactics.

6) Resources should be optimally utilized for human welfare and neither wasted nor destroyed in rifts, quarrels and battles.

7) The promoters of the rifts, quarrels and battles within different sectors of communities, Nations, groups and tribes should repent on their misdeeds, com- 
pensate the adversaries and World Court of Justice must be enabled to punish the culprits for world peace and welfare of human beings.

8) IBWT must be immediately reversed and any objection or reservation must be overruled.

9) The GAC be made optimally functional as early as possible concentrating all attentions, resources and means to this goal.

10) UNO and International Court of Justice be fully empowered and made completely independent Godfather to maintain worldwide peace and justice and scientifically mobilize the resources for welfare of the entire mankind.

\section{Acknowledgements}

Author is highly thankful to God for his help and guidance in elaboration of all the points of this issue and to all the authors and publishers whose information/data/graphs has been used directly or indirectly, modified or reset or reformatted for this and previous papers for sake of human and Global safety and welfare.

\section{Conflicts of Interest}

The author declares no conflicts of interest regarding the publication of this paper.

\section{References}

[1] Number of Reported Disasters by Type. https://ourworldindata.org/natural-disasters

[2] Major North Tropical Hurricanes, Our World in Data. https://ourworldindata.org/grapher/frequency-north-atlantic-hurricanes

[3] Cheng, L.J., et al. (2017) Improved Estimates of Ocean Heat Content from 1960 to 2015. Science Advances, 3, e1601545. http://advances.sciencemag.org/content/3/3/e1601545.full https://www.eurekalert.org/pub releases/2017-03/ioap-ans031317.php https://doi.org/10.1126/sciadv.1601545

[4] Church, J.A., et al. (2011) Revisiting the Earth's Sea-Level and Energy Budgets from 1961 to 2008. Geographical Research Letters, 38, L18601. https://www.skepticalscience.com/empirical-evidence-for-global-warming.htm https://doi.org/10.1029/2011GL048794

[5] Nuccitelli, D., Way, R., Painting, R., Church, J. and Cook, J. (2012) Comment on Ocean Heat Content and Earth's Radiation Imbalance. II. Relation to Climate Shifts. https://skepticalscience.com/docs/Comment on DK12.pdf https://doi.org/10.1016/j.physleta.2012.10.010

[6] Nazeer, M.M. (2019) Major Culprit behind Horrible Steep Rise of Global Heat Contents and Temperature Since 1973 and Its Reversal Strategy. International Journal of Scientific \& Engineering Research, 10, Paper ID: 10132594.

[7] Nazeer, M.M. (2019) Mobilization of Water Cycle and Its Persian Air Wheel Heat Pump to Overcome Global Heating and Its Resulting Terrible Environmental Problems. Open Access Library Journal, 6, e5445. https://doi.org/10.4236/oalib.1105445

[8] Annual Mean Temperature Change for Land and for Ocean NASA GISTEMP 2017 
October. From Wikimedia Commons, the Free Media Repository. https://commons.wikimedia.org/wiki/File:Annual Mean Temperature Change for Land and for Ocean NASA GISTEMP 2017 October.png

[9] Global Warming: Climate Change and Evolution. https://www.economist.com/democracy-in-america/2011/01/24/climate-change-an d-evolution

[10] Johnson, S.K. (2015) Updated NOAA Temperature Record Shows Little Global Warming Slowdown.

https://arstechnica.com/science/2015/06/updated-noaa-temperature-record-shows-1 ittle-global-warming-slowdown/

[11] https://www.eea.europa.eu/data-and-maps/indicators/global-and-european-temper ature/global-and-european-temperature-assessment-4

[12] Indus Water Treaty, World Bank Copy.

https://siteresources.worldbank.org/INTSOUTHASIA/Resources/223497-11057372 53588/IndusWatersTreaty1960.pdf

[13] https://youtu.be/qh011eAYjAA https://www.youtube.com/watch?v=qh011eAYjAA\&feature=youtu.be

[14] Tracks of Tropical Cyclones from 1842 to 2013. https://www.reddit.com/r/MapPorn/comments/1rde1j/tracks of tropical cyclones from 1842 to $2013 /$

https://en.wikipedia.org/wiki/Atlantic hurricane season http://i.imgur.com/nDAZNzL.jpg

[15] Nazeer, M.M. and Ather, N. (1998) Role of Earth Shape and Rotation in Generating and Tracking of Cyclones. Journal of Natural Science and Mathematics, 38, 217-227.

[16] Earth Globe Energy Budget.

https://www.researchgate.net/figure/Global-heat-budget-10-The-water-vapors-relat ed-heat-promotion-to-outflow-40-2CO2-and fig4 334086315 http://www.geocoops.com/uploads/2/4/5/3/24532387/1823846.jpg?804

[17] Von Schuckmann, K. (2017) Insights into the Role of the Oceans in the Earth Energy Budget. 5th International Conference on Reanalysis, Rome, 13-16 November 2017.

https://climate.copernicus.eu/sites/default/files/repository/Events/ICR5/Talks/9.ICR 5 KvS FINAL.pdf

[18] Nazeer, M.M. (2019) North Atlantic Hurricanes Take Birth in India and Can Be Moderated Only in Pakistan by Reversion of Their Agitator, the Indus Basin Water Treaty of 1960. International Journal of Scientific \& Engineering Research, 10, 461-481.

[19] Kelly, P., Leung, L.R., Balaguru, K., Xu, W.W., Mapes, B. and Soden, B. (2018) Shape of Atlantic Tropical Cyclone Tracks and the Indian Monsoon. Geographical Research Letter, 45, 10746-10755.

[20] Nazeer, M.M. (2019) Tragic Aftermath of Californian Jungle Fire and Hawaiian Volcano Outburst, a Warning about Persistently Rising Global Warming, Resulting into High Rated Disaster's Chain. Open Access Library Journal, 6, e5118. https://doi.org/10.4236/oalib.1105118

[21] Nazeer, M. (2020) New Insights in Prime Roles of Indian Subcontinent in Nurture of Global Heating and Hurricanes with Review of the Only Window for Their Calamities Control. Open Access Library Journal, 7: e6424. https://doi.org/10.4236/oalib.1106424

[22] Shortt, D. (2012) Some Details about Transits of Venus. https://www.planetary.org/blogs/guest-blogs/Some-Details-About-Transits-of-Ven us.html 
[23] https://www.scientificamerican.com/article/venus-crosses-the-sun-for/

[24] https://en.wikipedia.org/wiki/Transit of Venus

[25] https://en.wikipedia.org/wiki/Lunar precession

[26] Alladin, S.M and Ballabh, G.M. (2005) Dynamics of the Sun-Earth-Moon System. Resonance, 10, 6-24. https://www.ias.ac.in/article/fulltext/reso/010/08/0006-0024 https://doi.org/10.1007/BF02866743

[27] 100 Years Frequency of North Atlantic Hurricanes. 2015 Hurricane Update with NASA's Dr Tim Hall. https://insurancelinked.com/2015-hurricane-update-with-nasas-dr-tim-hall/

[28] NASA and Dartmouth Observatory. https://floodobservatory.colorado.edu/SiteDisplays/294.htm

[29] Federal Floods Commission, Ministry of Water and Resource. Government of Pakistan.

http://mowr.gov.pk/wp-content/uploads/2018/06/Annual-Flood-Report-of-FFC-20 17.pdf

[30] Annual Flood Report 2018. Government of Pakistan Ministry of Water Resources. https:/ffc.gov.pk/wp-content/uploads/2019/03/Annual-Flood-Report2018 2702201 9.pdf

[31] Ali, A. (2013) Indus Basin Floods Mechanisms, Impacts, and Management. Asian Development Bank.

[32] 7. 7 Escapage below Kotri Hydrological Year from April to March Source: WRMP WAPDA Based on Data Supplied by Govt. of Sindh.

https://www.slideshare.net/zubeditufail/water-and-power-development-authoritymega-dam-projects-press-briefing-december-16-2005

[33] Ahmad, S. (2007) Land and Water Resources of Pakistan-A Critical Assessment. The Pakistan Development Review, 46, 911-937.

https://www.pide.org.pk/pdf/PDR/2007/Volume4/911-937.pdf https://doi.org/10.30541/v46i4IIpp.911-937

[34] http://documents.worldbank.org/curated/en/251191548275645649/pdf/133964-WPPUBLIC-ADD-SERIES-22-1-2019-18-56-25-W.pdf

[35] Bhatt, C.M., Rao, G.S., Farooq, M.P., Manjusree, A., Shukla, S.V. and Sharma, S.P. (2017) Satellite-Based Assessment of the Catastrophic Jhelum Floods of September 2014, Jammu \& Kashmir, India. Geomatics, Natural Hazards and Risk, 8, 309-327. https://www.tandfonline.com/doi/full/10.1080/19475705.2016.1218943 https://doi.org/10.1080/19475705.2016.1218943

[36] Ahmad, D., Parvaze, S., Majid, M. and Kanth, R. (2016) Analysis of Historical Rainfall Data for Drought Investigation Using Standard Precipitation Index (SPI) under Temperate Conditions of Srinagar Kashmir. Pakistan Journal of Meteorology, 13, 29-38.

https://www.researchgate.net/publication/319058599 Analysis of Historical Rainf all Data for Drought Investigation Using Standard Precipitation Index SPI Un der Temperate Conditions of Srinagar Kashmir

[37] Nazeer, M.M. (2019) Reversal of Terrible Global Heating and Its Gang through Unique and Complete Water Evaporation and Precipitation Cycle of Pakistan. International Journal of Scientific \& Engineering Research, 10, 1244-1263.

[38] World Bank Report on Water and Power Resources of (Then) West Pakistan. http://documents.worldbank.org/curated/en/182331468758759382/pdf/multi0page.pdf http://documents.worldbank.org/curated/en/597841468098064172/pdf/multi0page.pdf http://documents.worldbank.org/curated/en/944011468091758375/pdf/multi0page.pdf 


\section{Abbreviations}

\begin{tabular}{cccc}
\hline Abbreviations & Stands for & Abbreviations & Stands for \\
\hline GHT & $\begin{array}{c}\text { Global Heat Contents and } \\
\text { Temperature }\end{array}$ & UIU & $\begin{array}{c}\text { Unscientific, illogical and } \\
\text { unnatural }\end{array}$ \\
GHC & Global Heat Contents & RCT & Rajasthan, Chulistan and Thar \\
GAC & Global Air Conditioner & SLB & Sea to land breeze \\
NAH & North Atlantic Hurricanes & LSB & Land to sea breeze \\
NAHHF & NAH 100 year frequency & C-rise & Celestial body rise on horizon \\
IBWT & Indus Basin water Treaty 1960 & C-setting & Setting down of celestial body \\
IAW & Indian Air Wheels & AESL & Along Earth-Sun line \\
\hline
\end{tabular}

